\title{
Polyurethane cuffed endotracheal tubes to prevent early postoperative pneumonia after cardiac surgery: A pilot study
}

Jan Poelaert, MD, PhD, ${ }^{\text {a,b }}$ Pieter Depuydt, MD, ${ }^{\mathrm{b}}$ Annick De Wolf, MD, ${ }^{\mathrm{b}}$ Stijn Van de Velde, MD, ${ }^{\mathrm{b}}$ Ingrid Herck, MD, and Stijn Blot, $\mathrm{PhD}^{\mathrm{b}, \mathrm{c}}$

From International Research Center, Ghent University, ${ }^{\mathrm{a}}$ the Department of Intensive Care Medicine, Ghent University Hospital, ${ }^{\text {b }}$ and Hogeschool Gent, Healthcare Department, ${ }^{\mathrm{c}}$ Gent, Belgium.

Supported by an unrestricted grant from the International Research Centre, Ghent University, to J.P. and a clinical doctoral grant Fund for Scientific Research Flanders (1.7.201.07.N.00) to P.D.

Received for publication Feb 23, 2007; revisions received Aug 16, 2007; accepted for publication Aug 23, 2007.

Address for reprints: Jan Poelaert, MD, PhD, Department of Anesthesiology, Free University Hospital Brussels, Laarbecklaan 101, 1090 Brussels, Belgium (E-mail: jan. poelaert@uzbrussels.be).

J Thorac Cardiovasc Surg 2008;135:771-6 $0022-5223 / \$ 34.00$

Copyright (C) 2008 by The American Association for Thoracic Surgery

doi:10.1016/j.jtcvs.2007.08.052
Objective: Patients receiving mechanical ventilation through an endotracheal tube are at increased risk for pneumonia. Because microaspiration of contaminated supraglottic secretions past the endotracheal tube cuff is considered to be central in the pathogenesis of ventilator-associated and postoperative pneumonia, better sealing of the upper trachea by the endotracheal tube cuff could possibly reduce this risk. We therefore postulated that use of a polyurethane cuffed tube would prevent early postoperative pneumonia through this mechanism in a population of cardiac surgical patients.

Methods: In a prospective, single-blind, randomized study, patients scheduled for cardiac surgery were allocated to intubation with a polyurethane cuffed endotracheal tube or the routinely used polyvinyl chloride cuffed endotracheal tube. Patients were scheduled for routine or emergency cardiac surgery and admitted to an 8-bed cardiac surgical intensive care unit of a tertiary care hospital.

Results: A total of 134 patients were available for analysis (67 in each group). Whereas mortality was not different between the groups, the incidence of early postoperative pneumonia and empirical prescription of antibiotic therapy were significantly lower in the polyurethane group than in the polyvinyl chloride group (23\% vs $42 \%, P<.03$ ). Intensive care unit and hospital stays were not significantly different between the two study subsets $(3 \pm 5$ days vs $3 \pm 4$ days and $16 \pm 9$ vs $17 \pm 11$ days, respectively). In a multivariate regression analysis, preoperative serum creatinine levels (odds ratio 1.85, confidence interval 1.02-3.37, $P=.04$ ) and perioperative transfusion (odds ratio 1.50, confidence interval 1.08-3.37, $P=.015$ ) were independently associated with increased risk of early postoperative pneumonia, whereas use of a polyurethane endotracheal tube was protective (odds ratio 0.31 , confidence interval $0.13-0.77, P=.01)$.

Conclusion: Polyurethane cuffed endotracheal tubes can reduce the frequency of early postoperative pneumonia in cardiac surgical patients.

$\mathrm{N}$ osocomial pneumonia is responsible for major infection-related mortality and morbidity in the intensive care unit (ICU). ${ }^{1-5}$ As much as $50 \%$ of attributable mortality has been reported, depending on case mix and appropriateness of early antibiotic therapy, and attributable morbidity is reflected by an excess ICU stay of 5 to 9 days. ${ }^{4}$ Moreover, clinically suspected nosocomial pneumonia is an important driver of antibiotic prescription, and consequently of selection pressure on ICU microbial flora. ${ }^{6-8}$ The risk of nosocomial pneumonia in critically ill patients increases 3 - to 20- fold if they receive mechanical ventilation through an endotracheal tube (ET) or cannula. ${ }^{1,9}$ Microaspiration of contaminated upper airway secretions along leaks and defects of the tracheal seal of the cuff is assumed to play a pivotal role in the development of intubation-related (ventilator-associated and postoperative) pneumonia. ${ }^{10-12}$ Advances in polymeric technology have permitted the development of a new generation of polyurethane (PU) cuffed ET. It was hypothesized that a better tracheal seal would 


\section{Abbreviations and Acronyms \\ $\mathrm{ET}=$ endotracheal tube \\ ICU $=$ intensive care unit \\ $\mathrm{PU}=$ polyurethane \\ $\mathrm{PVC}=$ polyvinyl chloride}

result from fewer folds and bends in the thinner cuff material, and thus microaspiration of potentially contaminated upper airway material could be reduced, ${ }^{13}$ theoretically leading to a lower incidence of pneumonia in intubated patients.

Cardiac surgical patients represent an important subset of patients at risk for postoperative pneumonia because of the universal and unavoidable application of invasive mechanical ventilation in supine positioning, the frequent use of intraoperative transesophageal echocardiography (promoting gastroesophageal regurgitation), and the systemic inflammatory response syndrome induced by surgical trauma. Respiratory infection is estimated to complicate the postoperative course of $5 \%$ to $20 \%$ of cardiac surgical patients. ${ }^{14-16}$ Because postoperative and ventilator-associated pneumonia have been identified as predictors of worse outcome in this particular patient category, strategies to prevent these pulmonary infections are strongly advocated. We assessed the potentially preventive role of PU cuffed ETs in the development of early postoperative pneumonia in a cohort of cardiac surgical patients in a single-blind, randomized, controlled trial.

\section{Materials and Methods Study Design}

A prospective, single-blind, randomized trial was conducted. Patients scheduled for cardiac surgery were randomly assigned to receive PU (Sealguard; Covidien, Mansfield, Mass) or a standard polyvinyl chloride (PVC; Mallinckrodt Inc, Hazelwood, Mo) high-volume, low-pressure cuffed ET at induction of anesthesia. Cuff volumes were comparable for the two cuff types. The attending ICU physician providing postoperative care, as well as the investigator collecting patient data and the microbiologist, were blinded to the assignment of ET type. Once positioned in the patient, both ET tubes were completely comparable in appearance, even to the trained eye. The study was approved by the institutional review board of the Ghent University Hospital, and all patients gave written informed consent.

\section{Patients and Procedures}

All patients scheduled for routine cardiac surgery or undergoing urgency or emergency cardiac surgery in the postoperative cardiac surgical ICU at our tertiary referral center were eligible for the study. Patients with pneumonia before surgery, with infectious endocarditis, or with current antibiotic therapy were excluded. Randomization occurred according to a computer-generated list, which was kept by the attending anesthesiologists, blinded for the intensivists. Female patients routinely received an ET with 8-mm internal diameter size, whereas male patients were intubated with a $9-\mathrm{mm}$ internal diameter ET, although the final decision was left to the discretion of the attending physician.
Immediately after endotracheal intubation and after closure of the sternum, cuff pressure was assessed by the attending anesthesiologist. Care was taken to maintain cuff pressures between 20 and $26 \mathrm{~cm} \mathrm{H}_{2} \mathrm{O}$ in both subsets. Intraoperative antibiotic prophylaxis consisted of cefazolin ( 2 g every 8 hours for 24 hours) in all cases.

After cardiac surgery, patients were transferred to the 8-bed cardiac surgical ICU for postoperative care and weaning from mechanical ventilation. Sedation was continued with propofol $(0.5-2 \mathrm{mg} /$ $[\mathrm{kg} \cdot \mathrm{h}]$ intravenously) as previously discussed. ${ }^{17}$ All patients received standard antacids with intravenous ranitidine $(50 \mathrm{mg}$ three times daily). Only vasoactive drugs like nitrates and sometimes isotopic drugs were administered. Cuff pressure was measured immediately on arrival and subsequently each 4 hours until extubation in all cases. Again, cuff pressures were monitored by attending nurses and carefully maintained between 20 and $26 \mathrm{~cm} \mathrm{H}_{2} \mathrm{O}$. Criteria for weaning and extubation included stable cardiovascular dynamics and metabolism, chest tube drainage less than $1 \mathrm{~mL} /(\mathrm{kg} \cdot \mathrm{h})$ for at least 2 consecutive hours, adequate gas exchange (defined as $\mathrm{PaO}_{2}$ $>70 \mathrm{~mm} \mathrm{Hg}$ with inspired oxygen fraction $\leq 0.6$, peak inspiratory pressure below $20 \mathrm{~cm} \mathrm{H}_{2} \mathrm{O}$, and peak end-expiratory pressure below $6 \mathrm{~cm} \mathrm{H}_{2} \mathrm{O}$ ), and adequate neurologic activity. ${ }^{18}$ Antibiotic prophylaxis consisted of cefazolin $(100 \mathrm{mg} /[\mathrm{kg} \cdot \mathrm{d}])$ and lasted 24 hours.

\section{Screening and Diagnosis}

After admission to the ICU, patients were screened daily for postoperative nosocomial pneumonia by the attending ICU physician, who was blinded to the ET tube allocation. Diagnosis of postoperative nosocomial pneumonia was defined before onset of the study. Because in our patient population microbial pathogens other than commensal flora are rarely isolated in this setting of early postoperative pneumonia, we aimed for higher specificity in our clinical diagnosis by requiring that all Johanson criteria, ${ }^{19}$ as well as two additional criteria, be fulfilled. ${ }^{20}$ Thus postoperative nosocomial pneumonia was defined as the presence of a new or evolving infiltrate on chest radiography within 7 days after surgery, together with the presence of all Johanson criteria ${ }^{19}$ : temperature greater than $38.2^{\circ} \mathrm{C}$, leukocytosis greater than 12,000 cells $/ \mathrm{mm}^{3}$, and presence of purulent sputum or endotracheal aspirate. Additional criteria were an increase in C-reactive protein for at least 2 consecutive days after surgery

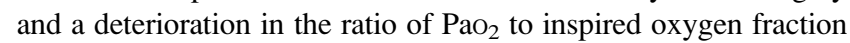
of at least $20 \%$. Diagnosis was made during the stay in the ICU by the attending intensivist, who was blinded to the assigned ET. Oropharyngeal and endotracheal aspirates were taken on ICU admission and on clinical suspicion of pneumonia. Microbial evaluation consisted of direct Gram staining and semiquantitative culture. As such, the initiation of antibiotic therapy was left to the discretion of the attending staff ICU physician. At our ICU, surveillance cultures are used to guide empirical antibiotic therapy in cases of suspected pneumonia. ${ }^{21,22}$ In the absence of surveillance cultures, empirical therapy for early (within 7 days after ICU admission) postoperative or ventilator-associated pneumonia without previous antibiotic exposure consists of cefuroxime or amoxicillin (INN amoxicilline) and clavulanate, with an antipseudomonal betalactam if pneumonia develops after 7 days or after previous antibiotic exposure. This empirical scheme is modified accordingly if surveillance cultures show the presence of multidrug-resistant organisms such as extended-spectrum $\beta$-lactamase-carrying Enterobacteriaceae or methicillin-resistant Staphylococcus aureus. 
TABLE 1. Characteristics and outcomes of patients intubated with polyurethane versus polyvinyl chloride cuffed endotracheal tubes

\begin{tabular}{|c|c|c|c|}
\hline & Polyvinyl (n = 67) & Polyurethane (n = 67) & $P$ value (univariate) \\
\hline Age $(y$, mean $\pm S D)$ & $67 \pm 11$ & $68 \pm 9$ & .70 \\
\hline Sex (male/female ratio) & $45: 22$ & $40: 27$ & .47 \\
\hline Body mass index $\left(\mathrm{kg} / \mathrm{m}^{2}\right.$, mean $\left.\pm \mathrm{SD}\right)$ & $27 \pm 5$ & $27 \pm 4$ & .38 \\
\hline Ejection fraction $(\%$, mean $\pm S D)$ & $60 \pm 17$ & $65 \pm 16$ & .10 \\
\hline Tu score (mean $\pm \mathrm{SD}$ ) & $4 \pm 3$ & $4 \pm 3$ & .58 \\
\hline EuroSCORE (mean \pm SD) & $5 \pm 4$ & $5 \pm 4$ & .38 \\
\hline Duration of surgery (min, mean \pm SD) & $265 \pm 60$ & $247 \pm 64$ & .10 \\
\hline Duration of ventilation ( $h$, mean $\pm S D$ ) & $25 \pm 36$ & $19 \pm 13$ & .22 \\
\hline Emergency surgery (No.) & 18 & 15 & .78 \\
\hline Packed red blood cells transfused (units, mean \pm SD) & $1 \pm 2$ & $1 \pm 1$ & .20 \\
\hline Early postoperative pneumonia (No.) & $28(42 \%)$ & $15(23 \%)$ & .026 \\
\hline Intensive care unit stay ( $d$, mean $\pm S D)$ & $3 \pm 4$ & $3 \pm 5$ & .87 \\
\hline Hospital stay (d, mean \pm SD) & $17 \pm 11$ & $16 \pm 9$ & .53 \\
\hline
\end{tabular}

\section{Variables Recorded and Calculated}

Two scoring systems were used, EuroSCORE ${ }^{23,24}$ and Tu score. ${ }^{25,26}$ Preoperative serum creatinine level and requirement for blood transfusion during or immediately after surgery (within 48 hours) were recorded. The primary end point was the occurrence of pneumonia within 3 days of cardiac surgery, considered to represent early postoperative pneumonia.

\section{Statistical Analysis}

The study was performed in two parts. A first, smaller part $(\mathrm{n}=30)$ allowed calculation of statistical power analysis (power .80, type II error .05), yielding a target sample size of 120 patients.

Data are expressed as mean $\pm \mathrm{SD}$. Continuous variables were assessed with ANOVA and when appropriate with an independent $t$ test. Categorical variables were analyzed with the $\chi^{2}$ test. Backward stepwise logistic regression analysis was performed to elucidate interfering factors for development of early postoperative pneumonia. To avoid spurious associations, only variables with a plausible relationship to the development of pneumonia or variables with a relationship in univariate analysis $(P=.20)$ were entered into the model. Statistical analyses were executed with the SPSS version 10 software package (SPSS Inc, Chicago, Ill).

\section{Results}

One hundred thirty-six patients (67 in the PU group and 69 in the PVC group) were enrolled in the study. Two patients in the PVC group died during surgery of refractory cardiogenic shock and were excluded from further analysis. Characteristics of patients are detailed in Table 1. No differences between the two groups were found with respect to age, body mass index, sex ratio, time on cardiopulmonary bypass, aortic crossclamp time, EuroSCORE, mean duration of mechanical ventilation, mortality, or length of stay in the ICU (Table 1). Early postoperative pneumonia was more frequently diagnosed in patients assigned to the PVC arm (28 [42\%] vs 15 [23\%], $P=.026)$; the relative risk on postoperative pneumonia associated with PU use was $0.42(0.20-0.89)$. No statisti- cal difference was found between the two groups with regard to length of stay in the ICU or in the hospital $(3 \pm 4$ days in the PVC group versus $3 \pm 5$ days in the PU subset and $17 \pm$ 11 days vs $16 \pm 9$ days, respectively). Table 2 shows no difference in frequency of the different types of surgical interventions.

\section{Outcome Measures}

Characteristics and outcomes in patients with and without diagnosis of early postoperative pneumonia are shown in Table 3. Patients with pneumonia had a similar mortality to that of patients without pneumonia but significantly longer ICU and hospital stays $(5 \pm 7$ days vs $2 \pm 1$ days, $P=.003$, and $21 \pm$ 15 days vs $14 \pm 6$ days, $P=.004$, respectively). No patients required reintubation. Other potentially influencing factors are listed in Table 4. Microbial etiology of early postoperative pneumonia was documented in 15 cases (Table 5); all pathogens were susceptible to instituted empirical antibiotic therapy, which consisted of cefuroxime for 5 to 7 days.

To correct for imbalances between the patient groups assigned to PU versus PVC that might confound the association

TABLE 2. Surgical comparison of patients intubated with polyurethane versus polyvinyl chloride cuffed endotracheal tubes

\begin{tabular}{lcc}
\hline & $\begin{array}{c}\text { Polyvinyl } \\
\text { (n= 67) }\end{array}$ & $\begin{array}{c}\text { Polyurethane } \\
\text { (n= 67) }\end{array}$ \\
\hline $\begin{array}{l}\text { Coronary artery bypass grafting } \\
\text { Combined } \\
\quad \text { Coronary artery bypass } \\
\quad \text { grafting + valve }\end{array}$ & 37 & 37 \\
$\quad 1$ valve & 0 & 12 \\
$\begin{array}{l}\text { Single-valve surgery } \\
\text { Aortic surgery }\end{array}$ & 16 & 1 \\
\hline
\end{tabular}

No statistically significant difference between the two groups was seen. 
TABLE 3. Characteristics and outcomes of patients with and without early postoperative pneumonia

\begin{tabular}{lccc}
\hline & Pneumonia $(\mathbf{n}=\mathbf{4 3})$ & No pneumonia $(\mathbf{n}=\mathbf{9 1})$ & P value (univariate) \\
\hline Age (y, mean \pm SD) & $70 \pm 9$ & $66 \pm 10$ & .025 \\
Sex (male/female ratio) & $28: 15$ & $54: 35$ & .763 \\
Ejection fraction (\%, mean \pm SD) & $58 \pm 18$ & $64 \pm 16$ & .038 \\
Body mass index (kg/m², mean \pm SD) & $32 \pm 2$ & $27 \pm 5$ & .216 \\
Creatinemia (mg/dL) & $1.6 \pm 1.5$ & $1.1 \pm 0.5$ & .035 \\
Tu score (mean \pm SD) & $5 \pm 3$ & $3 \pm 3$ & .034 \\
EuroSCORE (mean \pm SD) & $7 \pm 4$ & $4 \pm 3$ & .001 \\
Duration of surgery (min, mean \pm SD) & $256 \pm 75$ & $257 \pm 57$ & .944 \\
Duration of ventilation (h, mean \pm SD) & $31 \pm 45$ & $18 \pm 11$ & .052 \\
Packed red blood cells (units, mean \pm SD) & $2 \pm 2$ & $1 \pm 1$ & .010 \\
Polyurethane tube present (No.) & $15(35 \%)$ & $50(56 \%)$ & .026 \\
ICU stay (d, mean \pm SD) & $5 \pm 7$ & $2 \pm 1$ & .003 \\
Hospital stay (d, mean \pm SD) & $21 \pm 15$ & $14 \pm 6$ & .004 \\
\hline
\end{tabular}

between ET type and early postoperative pneumonia, a multivariate analysis was performed (Table 6). In backward stepwise logistic regression, elevated preoperative serum creatinine level (odds ratio 1.85, confidence interval 1.02$3.37, P=.04$ ) and perioperative transfusion (odds ratio 1.50 per unit of packed cells required, confidence interval $1.08-3.37, P=.015)$ were independently associated with increased risk of early postoperative pneumonia, whereas allocation to the PU group was associated with a lower risk (odds ratio 0.31 , confidence interval $0.13-0.77, P=.01$; Table 6).

\section{Discussion}

In this randomized, controlled trial, use of a PU cuffed ET during cardiac surgery was associated with a roughly $50 \%$ decrease in early postoperative pneumonia. To the best of our knowledge, this is the first study to demonstrate a protective effect from the use of a PU cuffed tube against the development of early postoperative pneumonia in clinical practice. Because nosocomial pneumonia has been identified as an

TABLE 4. Frequencies of preoperative risk factors that could facilitate the development of postoperative pneumonia

\begin{tabular}{lcccccc}
\hline & \multicolumn{2}{c}{$\begin{array}{c}\text { Pneumonia } \\
\text { present }\end{array}$} & & \multicolumn{2}{c}{$\begin{array}{c}\text { Pneumonia } \\
\text { absent }\end{array}$} \\
\cline { 2 - 3 } \cline { 6 - 7 } \multicolumn{1}{c}{ Variable } & $\begin{array}{c}\text { PVC } \\
\text { (n = 39) }\end{array}$ & $\begin{array}{c}\text { PU } \\
\text { (n = 52) }\end{array}$ & & $\begin{array}{c}\text { PVC } \\
\text { (n = 28) }\end{array}$ & $\begin{array}{c}\text { PU } \\
(\mathbf{n}=\mathbf{1 5})\end{array}$ \\
\hline Reoperation & 2 & 3 & & 2 & 3 \\
Intra-aortic balloon pump & 5 & 4 & & 7 & 4 \\
Diabetes & 9 & 15 & & 8 & 7 \\
Chronic obstructive & 5 & 8 & & 2 & 1 \\
$\quad$ pulmonary disease & & & & & \\
Pulmonary hypertension & 7 & 6 & & 8 & 3 \\
Tobacco use & 19 & 17 & & 13 & 3 \\
Chronic renal failure & 7 & 11 & & 11 & 6 \\
\hline
\end{tabular}

No statistically signific ant differences were seen $\left(\Pi^{2}\right.$ test). $P U$, Polyurethane cuffed endotracheal tube; $P V C$, polyvinyl chloride cuffed endotracheal tube. independent risk factor for mortality through development of multiple organ failure, both in the general ICU population $^{1,4,7,22}$ and in postoperative cardiac surgical patients in particular, ${ }^{15,16,27}$ the importance of preventive strategies cannot be overestimated. Whenever a pneumonia was present, independently of the tube used, increased lengths of stay (both ICU and hospital) were observed (Table 3). With regard to the two subsets of patients, however, no overall difference of length of stay in the ICU or the hospital could be shown (Table 1).

Prevention of early postoperative pneumonia is to be achieved through a multimodality and multidisciplinary effort. ${ }^{11,28}$ Strategies to disrupt the sequence of oral colonization with pathogenic organisms, followed by dislocation of this contaminated material into the lower airways through defective upper airway barriers and subsequent development of tracheobronchitis and ultimately pneumonia, however, play a central role in each preventive program. Semirecumbent positioning, rather than supine positioning, of ventilated patients (especially when enterally fed) has been conclusively shown to decrease the risk of early postoperative and ventilator-associated pneumonia, as has to a lesser extent the practice of continuous suctioning of subglottic secretions. ${ }^{28,29}$

TABLE 5. Bacteria isolated from tracheal aspirates (threshold at least $10^{5}$ colony-forming units $/ \mathrm{mL}$ )

\begin{tabular}{lcc}
\hline & $\begin{array}{c}\text { Polyurethane } \\
\text { (n= 67) }\end{array}$ & $\begin{array}{c}\text { Polyvinyl } \\
\text { (n= 67) }\end{array}$ \\
\hline Negative cultures & 11 & 16 \\
Commensal flora & 2 & 6 \\
Escherichia coli & 1 & 1 \\
Pseudomonas aeruginosa & 1 & 1 \\
Serratia species & 0 & 1 \\
Klebsiella species & 0 & 1 \\
Citrobacter species & 0 & 1 \\
Enterobacter species & 0 & 1 \\
\hline
\end{tabular}


TABLE 6. Multivariable regression analysis (backward stepwise) of factors associated with diagnosis of early ventilatorassociated pneumonia $(\mathrm{n}=\mathbf{1 2 9})$

\begin{tabular}{lcccc}
\hline \multicolumn{1}{c}{ Predictor } & Parameter estimate & Odds ratio & Confidence interval & P value \\
\hline Preoperative serum creatininemia & 0.62 & 1.85 & $1.02-3.37$ & .04 \\
Units transfused of packed red blood cells & 0.41 & 1.50 & $1.08-3.37$ & .015 \\
Polyurethane cuffed endotracheal tube & -1.17 & 0.31 & $0.13-0.77$ & .01 \\
Constant & -1.5 & &
\end{tabular}

Parameters included were as follows: EuroSCORE, duration of mechanical ventilation, preoperative serum creatininemia, units of perioperatively transfused packed blood cell, use of polyurethane cuffed endotracheal tube. Hosmer-Lemeshow goodness of fit, $\Pi^{2}{ }_{8} P=.92$, area under receiver operating curve $0.73 \pm 0.05$.

A recent multicenter trial reported reduced lower bacterial airway colonization associated with the use of a silver-coated ET, probably through the topical antimicrobial effect of silver ions, although a reduction in prevalence of subsequent pneumonia was not observed. ${ }^{30}$ From this perspective, decreasing leakage of contaminated upper airway secretions through folds and channels between (partially) inflated ET cuffs and tracheal wall can be considered as part of the central core of preventive measures, especially in circumstances where semirecumbent positioning is not possible, such as during cardiac surgery. Altering the material of the cuff from PVC to PU permits a thinner cuff wall, which therefore expands more completely and follows internal diameter of the trachea more closely when the cuff is inflated. ${ }^{13}$

Table 6 discloses that the type of ET tube was a stronger predictor than either the number of packed red cell units transfused or preoperative renal function. In a large retrospective study on risk factors for postoperative infection in cardiac surgery, blood bank requirements, among many other factors, were associated with postoperative infection risk. ${ }^{31}$ and Corwin and associates ${ }^{32}$ identified transfusion as an independent risk factor for ventilator-associated pneumonia in a general ICU population. Insofar as transfusion policy is dependent on predefined transfusion thresholds, rather than reflecting perioperative complications, this may prove to be a modifiable risk factor as well. Nevertheless, prevention of postoperative pneumonia appears to be far more important.

Some drawbacks and shortcomings of this investigation should be mentioned. A major flaw of this investigation could be the lack of microbiologic confirmation of most episodes of postoperative pneumonia. This may in part have been due to the postoperative setting in which this study was conducted. All patients received intraoperative antibiotic prophylaxis (with a first-generation cephalosporin), which probably has prevented subsequent isolation of microbial pathogens causing early-onset pneumonia, because these are known to be reflective of patients' endogenous flora rather than potentially multidrug-resistant nosocomial flora. In addition, because most patients were already extubated when pneumonia was considered clinically likely, part of this low yield may have been caused by difficulties in obtaining a good quality lower airway microbiologic sample. Alternatively, because a clinical diagnosis of nosocomial pneumonia suffers from lack of specificity, ${ }^{19}$ it could be argued that some of the episodes of postoperative pneumonia were in fact noninfectious complications mimicking pneumonia, such as aspiration pneumonitis, acute lung injury, or atelectasis. Clearly, there is need for more discriminative diagnostic tests for nosocomial pneumonia, in particular ventilator-associated pneumonia, to reduce unnecessary antibiotic therapy. Because invasive microbiologic sampling was not judged feasible for our fragile, recently extubated patient population, and additional diagnostic tests such as procalcitonin are not yet validated for nosocomial pneumonia ${ }^{33}$ and were not available to us, a clinical diagnosis of pneumonia was the best we could offer. Moreover, this clinically based diagnosis is reflective of widespread clinical practice, with additional variables increasing specificity to $92 \% .^{20,34}$ It is important to mention that our ICU physicians responsible for postoperative care, including diagnosis and antibiotic treatment of likely pneumonia, were blinded to the patient allocation.

At the very least, our study shows that use of a PU cuffed tube is able to decrease early postoperative antibiotic prescription by half. This reduction may have a favorable effect indirectly, because empirical postoperative antibiotic therapy itself has been found to increase the risk for nosocomial infection in cardiac surgical patients. ${ }^{35}$ Our results may not be readily extrapolated to the general ICU population. All our patients were intubated in the setting of anesthetic induction for cardiac surgery, so risk for significant aspiration during this procedure was kept to a minimum. In an unplanned or emergency resuscitation, significant aspiration of oropharyngeal content into the lower airways may happen before or during airway intubation, diminishing the preventive effect of a tighter tracheal seal once the ET is in place. Because the duration of mechanical ventilation in our patients was short, it has yet to be established whether a PU cuffed ET would limit endotracheal microaspiration during prolonged mechanical ventilation.

Another issue might be that some results are skewed, in particular with respect to ejection fraction and surgery duration (Table 1). A clinical difference was nonexistent, however, and the presence of comparable scoring indices could preclude this potential impact.

In conclusion, use of a PU cuffed ET instead of a standard PVC cuffed ET during cardiac surgery could significantly 
decrease the occurrence of clinically suspected pneumonia in the early postoperative phase and subsequently reduce the use of empirical antibiotic therapy. A larger randomized trial is desirable to confirm this finding and to examine whether it holds true when a more rigid, microbiologically centered diagnosis of pneumonia is applied. In the absence of a reliable diagnostic strategy for ventilator-associated pneumonia or postoperative pneumonia, however, use of a PU cuffed ET in cardiac surgery can still be advocated as an antibioticreducing and cost-effective strategy.

\section{References}

1. Chastre J, Fagon JY. Ventilator-associated pneumonia. Am J Respir Crit Care Med. 2002;165:867-903.

2. Rello J, Ollendorf DA, Oster G, Vera-Llonch M, Bellm L, Redman R, et al. Epidemiology and outcomes of ventilator-associated pneumonia in a large US database. Chest. 2002;122:2115-21.

3. Rello J, Quintana E, Ausina V, Castella J, Luquin M, Net A, et al. Incidence, etiology, and outcome of nosocomial pneumonia in mechanically ventilated patients. Chest. 1991;100:439-44.

4. Safdar N, Dezfulian C, Collard HR, Saint S. Clinical and economic consequences of ventilator-associated pneumonia: a systematic review. Crit Care Med. 2005;33:2184-93.

5. Tejerina E, Frutos-Vivar F, Restrepo MI, Anzueto A, Abroug F, Palizas F, et al. Incidence, risk factors, and outcome of ventilator-associated pneumonia. J Crit Care. 2006;21:56-65.

6. Bergmans DC, Bonten MJ, Gaillard CA, van Tiel FH, van der Geest S, de Leeuw PW, et al. Indications for antibiotic use in ICU patients: a one-year prospective surveillance. J Antimicrob Chemother. 1997;39: 527-35.

7. Kollef MH. What is ventilator-associated pneumonia and why is it important? Respir Care. 2005;50:714-24.

8. Singh N, Falestiny MN, Rogers P, Reed MJ, Pularski J, Norris R, et al. Pulmonary infiltrates in the surgical ICU: prospective assessment of predictors of etiology and mortality. Chest. 1998;114:1129-36.

9. Cook DJ, Walter SD, Cook RJ, Griffith LE, Guyatt GH, Leasa D, et al. Incidence of and risk factors for ventilator-associated pneumonia in critically ill patients. Ann Intern Med. 1998;129:433-40.

10. Jacobs R, Wiener-Kronish J. Endotracheal tubes: the conduit for oral and nasal microbial communities to the lungs. Anesthesiology. 2006;104: 224-5.

11. Kollef MH. Prevention of hospital-associated pneumonia and ventilatorassociated pneumonia. Crit Care Med. 2004;32:1396-405.

12. Safdar N, Crnich CJ, Maki DG. The pathogenesis of ventilator-associated pneumonia: its relevance to developing effective strategies for prevention. Respir Care. 2005;50:725-41.

13. Dullenkopf A, Gerber A, Weiss M. Fluid leakage past tracheal tube cuffs: evaluation of the new Microcuff endotracheal tube. Intensive Care Med. 2003;29:1849-53.

14. Bouza E, Hortal J, Muñoz P, Pérez MJ, Riesgo MJ, Hiesmayr M; European Study Group on Nosocomial Infections and the European Workgroup of Cardiothoracic Intensivists. Infections following major heart surgery in European intensive care units: there is room for improvement (ESGNI 007 Study). J Hosp Infect. 2006;63:399-405.

15. Bouza E, Pérez A, Muñoz P, Jesús Pérez M, Rincón C, Sánchez C. Ventilator-associated pneumonia after heart surgery: a prospective analysis and the value of surveillance. Crit Care Med. 2003;31:1964-70.

16. Kollef MH, Sharpless L, Vlasnik J, Pasque C, Murphy D, Fraser VJ. The impact of nosocomial infections on patient outcomes following cardiac surgery. Chest. 1997;112:666-75.
17. Schmidt C, Roosens C, Struys M, Deryck YL, Van Nooten G, Colardyn F. Contractility in humans after coronary artery surgery. Anesthesiology. 1999;91:58-70.

18. Straka Z, Brucek P, Vanek T, Votava J, Widimsky P. Routine immediate extubation for off-pump coronary artery bypass grafting without thoracic epidural analgesia. Ann Thorac Surg. 2002;74:1544-7.

19. Johanson WG Jr, Pierce AK, Sanford JP, Thomas GD. Nosocomial respiratory infections with gram-negative bacilli. The significance of colonization of the respiratory tract. Ann Intern Med. 1972;77:701-6.

20. Fàbregas N, Ewig S, Torres A, El-Ebiary M, Ramirez J, de La Bellacasa JP, et al. Clinical diagnosis of ventilator associated pneumonia revisited: comparative validation using immediate post-mortem lung biopsies. Thorax. 1999;54:867-73.

21. Depuydt P, Benoit D, Vogelaers D, Claeys G, Verschraegen G, Vandewoude K, et al. Outcome in bacteremia associated with nosocomial pneumonia and the impact of pathogen prediction by tracheal surveillance cultures. Intensive Care Med. 2006;32:1773-81.

22. Depuydt P, Myny D, Blot S. Nosocomial pneumonia: aetiology, diagnosis and treatment. Curr Opin Pulm Med. 2006;12:192-7.

23. Nashef SA, Roques F, Michel P, Cortina J, Faichney A, Gams E, et al. Coronary surgery in Europe: comparison of the national subsets of the European system for cardiac operative risk evaluation database. Eur J Cardiothorac Surg. 2000;17:396-9.

24. Nashef SA, Roques F, Michel P, Gauducheau E, Lemeshow S, Salamon R. European system for cardiac operative risk evaluation (EuroSCORE). Eur J Cardiothorac Surg. 1999;16:9-13.

25. Tu JV, Jaglal SB, Naylor CD. Multicenter validation of a risk index for mortality, intensive care unit stay, and overall hospital length of stay after cardiac surgery. Steering Committee of the Provincial Adult Cardiac Care Network of Ontario. Circulation. 1995;91:677-84.

26. Tu JV, Sykora K, Naylor CD. Assessing the outcomes of coronary artery bypass graft surgery: how many risk factors are enough? Steering Committee of the Cardiac Care Network of Ontario. J Am Coll Cardiol. 1997; 30:1317-23.

27. Falagas ME, Rosmarakis ES, Rellos K, Michalopoulos A, Samonis G, Prapas SN. Microbiologically documented nosocomial infections after coronary artery bypass surgery without cardiopulmonary bypass. J Thorac Cardiovasc Surg. 2006;132:481-90.

28. Craven DE. Preventing ventilator-associated pneumonia in adults: sowing seeds of change. Chest. 2006;130:251-60.

29. Dodek P, Keenan S, Cook D, Heyland D, Jacka M, Hand L, et al. Evidence-based clinical practice guideline for the prevention of ventilator-associated pneumonia. Ann Intern Med. 2004;141:305-13.

30. Rello J, Kollef M, Diaz E, Sandiumenge A, del Castillo Y, Corbella X. Reduced burden of bacterial airway colonization with a novel silvercoated endotracheal tube in a randomized multiple-center feasibility study. Crit Care Med. 2006;34:2766-72.

31. Göl MK, Karahan M, Ulus AT, Erdil N, Iscan Z, Karabiber N, et al. Bloodstream, respiratory, and deep surgical wound infections after open heart surgery. J Card Surg. 1998;13:252-9.

32. Corwin HL, Gettinger A, Pearl RG, Fink MP, Levy MM, Abraham E, et al. The CRIT Study: Anemia and blood transfusion in the critically ill-current clinical practice in the United States. Crit Care Med. 2004;32:39-52.

33. Chastre J, Luyt CE, Trouillet JL, Combes A. New diagnostic and prognostic markers of ventilator-associated pneumonia. Curr Opin Crit Care. 2006;12:446-51.

34. Póvoa P, Coelho L, Almeida E, Fernandes A, Mealha R, Moreira P, et al. $\mathrm{C}$-reactive protein as a marker of ventilator-associated pneumonia resolution: a pilot study. Eur Respir J. 2005;25:804-12.

35. Kollef M, Skubas N, Sundt T. A randomized trial of continuous aspiration of subglottic secretions in cardiac surgery patients. Chest. 1999;116: 1339-46. 